\title{
Imaging of Tropical Chronic Pancreatitis-A Unique Clinico-Radiological Entity
}

\author{
Chinmay Bhimaji Kulkarni ${ }^{1}$ Resmi Sekhar ${ }^{1}$ Srikanth Moorthy ${ }^{1} \quad$ Sreekumar Karumathil Pullara ${ }^{1}$ \\ Nirmal Kumar Prabhu ${ }^{1}$ Ramiah Rajesh Kannan ${ }^{1}$
}

1Department of Radiology, Amrita Institute of Medical Sciences, Amrita Lane, Ponekkara, Cochin, Kerala state, India

\begin{abstract}
Address for correspondence Chinmay Bhimaji Kulkarni, Department of Radiology, Amrita Institute of Medical Sciences and Research Centre, Amrita Lane, Ponekkra, Elamakkara P.O., Kochi 682041, Kerala, India (e-mail: chidoc@rediffmail.com; drchinmaykulkarni@gmail.com).
\end{abstract}

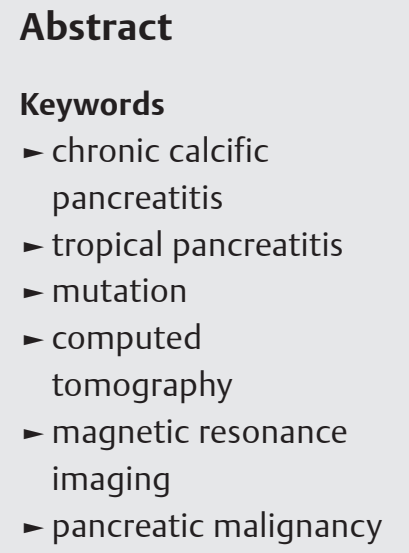

\section{Introduction}

Tropical chronic pancreatitis (TCP) is a unique juvenile nonalcoholic form of chronic pancreatitis prevalent in tropical developing countries. TCP is characterized by the younger age of onset, rapid progression, higher prevalence of diabetes and pancreatic calculi, and higher propensity to develop pancreatic malignancy. The usual clinical scenario of TCP can be witnessed in a child, adolescent or young adult presented with recurrent attacks of abdominal pain, steatorrhea, and diabetes which usually sets in by the third decade. The diabetic stage of the disease is referred to as fibrocalculous pancreatic diabetes. The diabetes is severe and requires high doses of insulin although ketosis is uncommon. Demonstration of high blood sugar level and pancreatic calculi on imaging confirms the diagnosis. ${ }^{1,2}$ Zuidema from Indonesia was the first to describe a series of 45 cases of TCP. ${ }^{3}$ Geevarghese et al reported the largest series of TCP in the world from the south-western Indian state of Kerala. ${ }^{4,5}$ The prevalence of chronic pancreatitis in the Western population is 10 to 15 per 100,000 , which is considerably lesser compared with the prevalence of 120 to 200 per 100,000 in certain parts of south India. ${ }^{1}$ TCP is unique compared with other forms of chronic pancreatitis in its etiology, imaging features, and prognosis. In this article, we review the etiopathogenesis and distinct imaging features and complications of TCP.

\section{Etio-Pathogenesis}

Malnutrition, consumption of cassava, viral infection, and familial and genetic factors have been implicated in the causation of TCP. The main mechanism of pancreatic damage (acinar cell injury) is autodigestion by trypsin. Mutations in genes that prevent premature activation of trypsinogen to trypsin lead to pancreatitis. Mutations with high prevalence in TCP are serine protease inhibitor (SPINK 1), cationic trypsinogen gene (PRSS 1), and cystic fibrosis transmembrane conductance regulator (CFTR) gene. A recent study from India showed a high association of tropical pancreatitis with SPINK N34S mutation. These mutations are believed to lead toward 
sentinel pancreatitis, and combined with other exogenous factors precipitate further recurrent episodes of pancreatitis in predisposed patients (- Fig. 1). ${ }^{6-14}$

\section{Pathology}

The morphological features of pancreas depend on the duration and severity of the disease. Parenchymal atrophy is variable and the size of gland is inversely proportional to duration. Fibrosis is the most important microscopic finding and also the main cause of atrophy of the gland. In advanced stages, the gland is replaced by adipose tissue. The pancreatic ducts show areas of stenosis and dilatation. The characteristic intraductal calculi of varying size (millimetric to $5 \mathrm{~cm}$ ) are observed. The core organic matrix of calculi consists of desquamated epithelium, fibrin, mucin, and protein deposits. Later, calcium (predominantly in form of calcium carbonate) deposits in the periphery of this matrix. ${ }^{15-19}$

The characteristic microscopic finding in TCP is the periductular fibrosis, predominantly involving the main duct and small ductules leading to marked dilatation of the ducts. ${ }^{20}$ Immunohistochemistry has shown an overall decrease in the percent of $\alpha$ cells and $\beta$ cells. The decrease in insulin positivity in the islets is often inversely proportional to the duration of diabetes. ${ }^{21}$

\section{Imaging}

Imaging and diagnosis of TCP are almost never made in the early stages, as the dominant symptom of abdominal pain is non-specific. The imaging feature depends on the stage of the disease. In the early stages, small calculi can be detected only on computed tomography (CT) or ultrasound and can be easily missed on plain radiographs. Ultrasound is a useful tool to regularly follow up these patients and to detect complications. ${ }^{22-25}$ When the pancreatic parenchyma is completely replaced by the fat, the echogenic fat on an ultrasound could mimic the normal pancreas (-Fig. 2). CT is the modality of choice, as it allows complete visualization of the gland, detection of calcifications, and identification of associated complications. ${ }^{26,27}$ As the onset of TCP is at a younger age, these patients require frequent imaging for early detection of the complications/neoplasm. Although CT is a sensitive tool, the cumulative radiation dose is a cause for concern. Magnetic Resonance Imaging (MRI) is an excellent modality to delineate the ductal anatomy and conduct follow-up imaging of younger patients. However, when the ducts are packed with the calculi, visualization of the ducts on magnetic resonance cholangiopancreatography (MRCP) is compromised (-Fig. $\mathbf{3}$ ).

\section{Pancreatic Parenchyma and Pancreatic Duct}

Pancreatic size is inversely proportional to the duration of the disease. The degree of duct dilatation also increases as the disease progresses. Diffuse and massive main ductal dilatation is a common pattern (-Fig. 4). However, focal dilatation involving either head, body, or tail region can also be observed.

\section{Pancreatic Calculi}

Identifying the characteristic distribution of calculi is a crucial factor in establishing the diagnosis of TCP. The stones range in size from small sand-like particles to $5 \mathrm{~cm}$. Usually, the stones in the head region are larger and denser, whereas size and density progressively decrease toward the tail region. The shape of calculi depends on location and may be smooth elongated, rounded, or staghorn shape. Various distribution patterns can be identified in TCP. The most common and characteristic

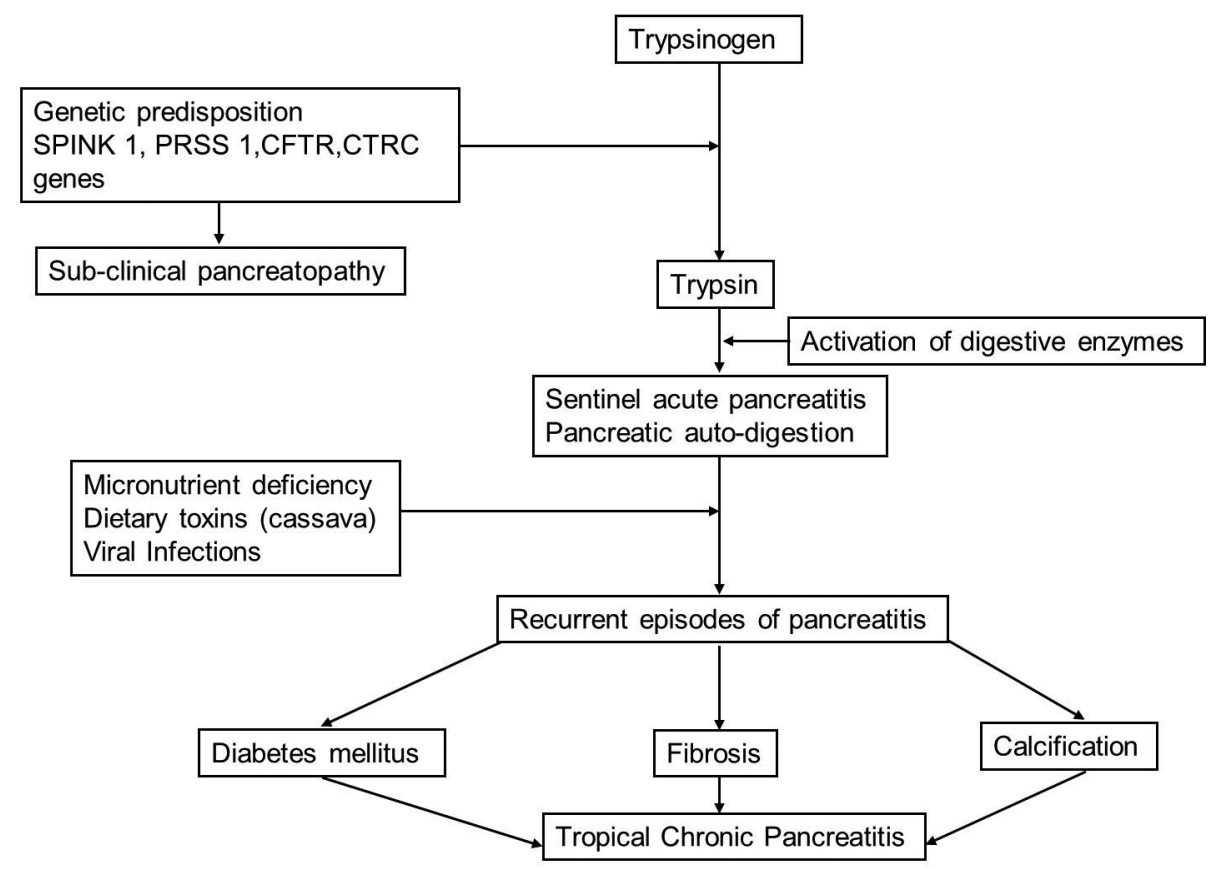

Fig. 1 Aetio-Pathogenesis of Tropical Chronic Pancreatitis. 

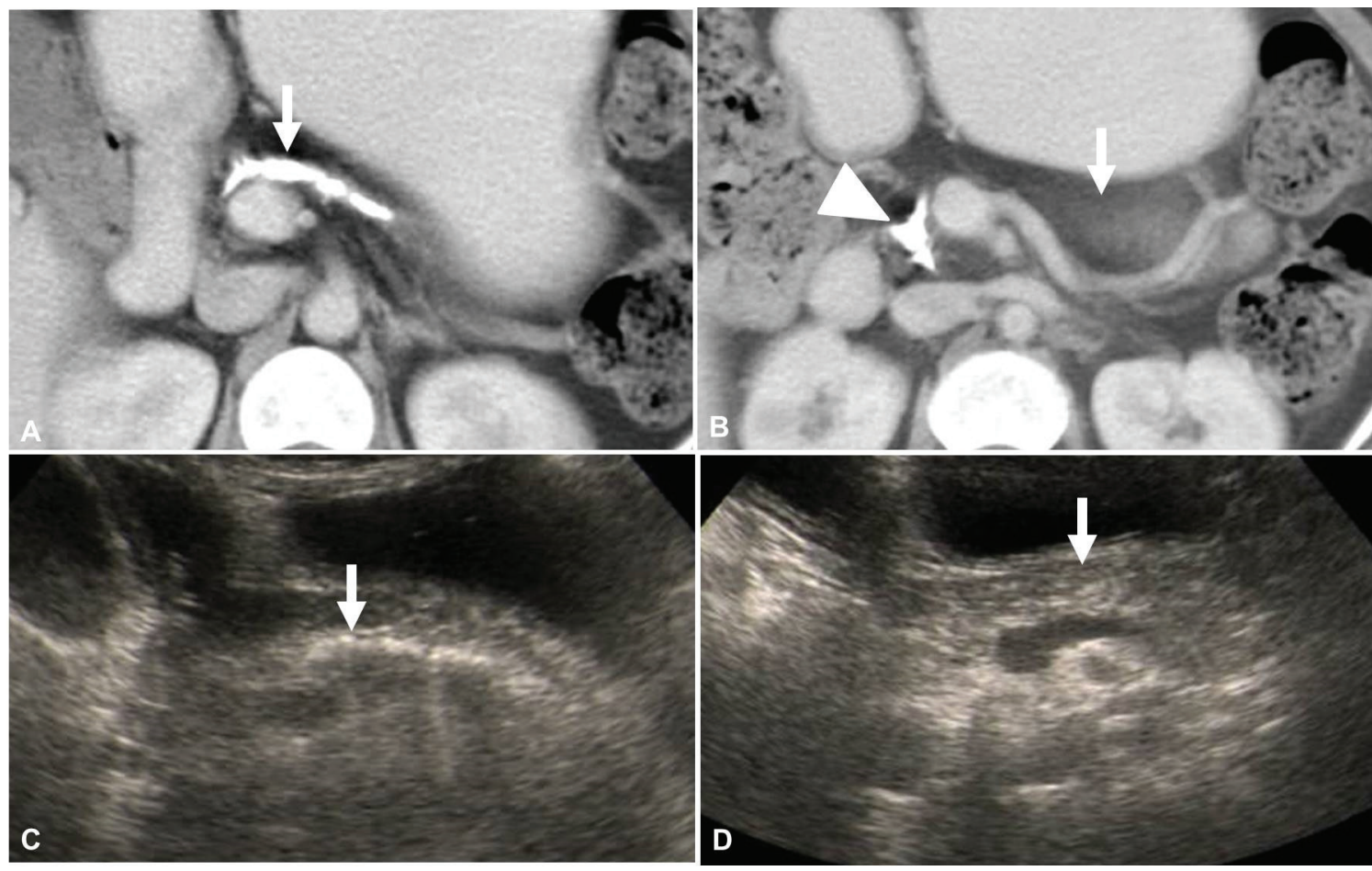

Fig. 2 An 18-year-old male patient with tropical chronic pancreatitis (TCP) and diabetes mellitus. Contrast CT axial images (A, B), Ultrasonography images (C, D) show pancreatic parenchyma completely replaced by fat (B, arrow). Echogenic fat on ultrasound can mimic normal pancreas (D, arrow). Note the dilated main pancreatic duct (MPD) with intraductal calculi (A, C arrow).

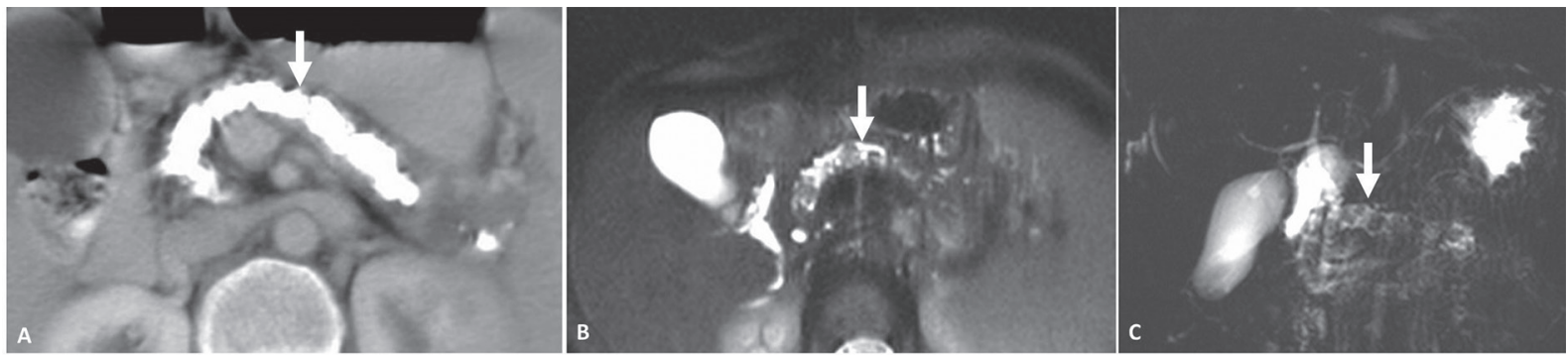

Fig. 3 A 20-year-old male patient with tropical chronic pancreatitis (TCP) and diabetes mellitus. Contrast CT axial images (A), T2 weighted MR axial image (B), MRCP image (C) show dilated main pancreatic duct (MPD) packed with the calculi (A, arrow). Packed intraductal calculi cause difficulty in the visualization of the pancreatic duct on MRI (B, arrow) and MRCP (C, arrow) images.

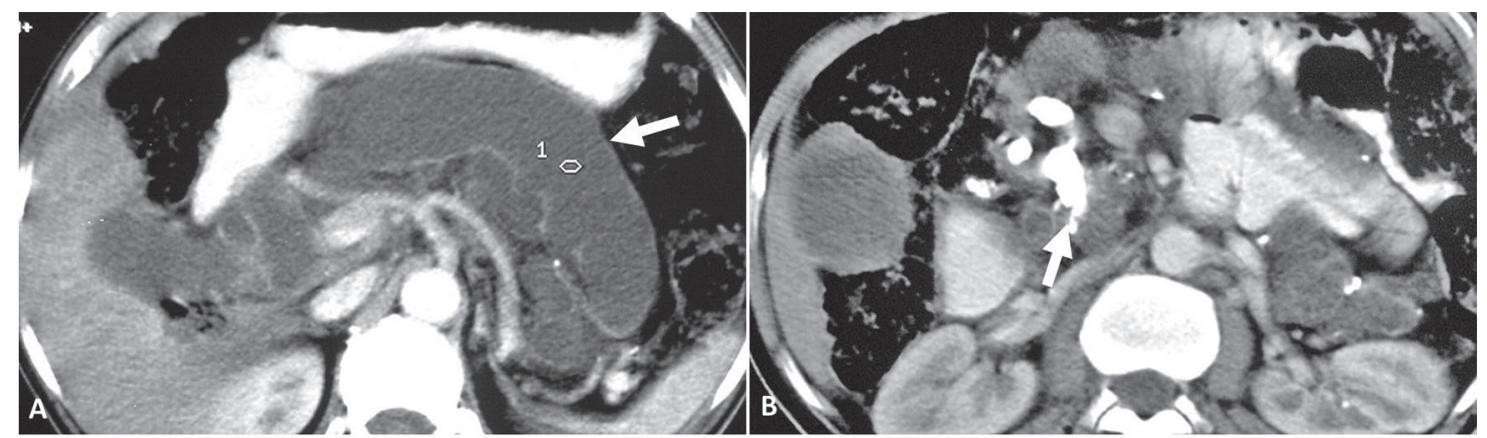

Fig. 4 A 25-year-old male patient with tropical chronic pancreatitis (TCP) and diabetes mellitus. Axial images (A, B) of contrast CT shows completely atrophic pancreas (not visualized), hugely dilated main pancreatic duct (A, arrow) and large intraductal calculi in the head region of the pancreas (B, arrow). Note absence of calculi in the body and tail region. 


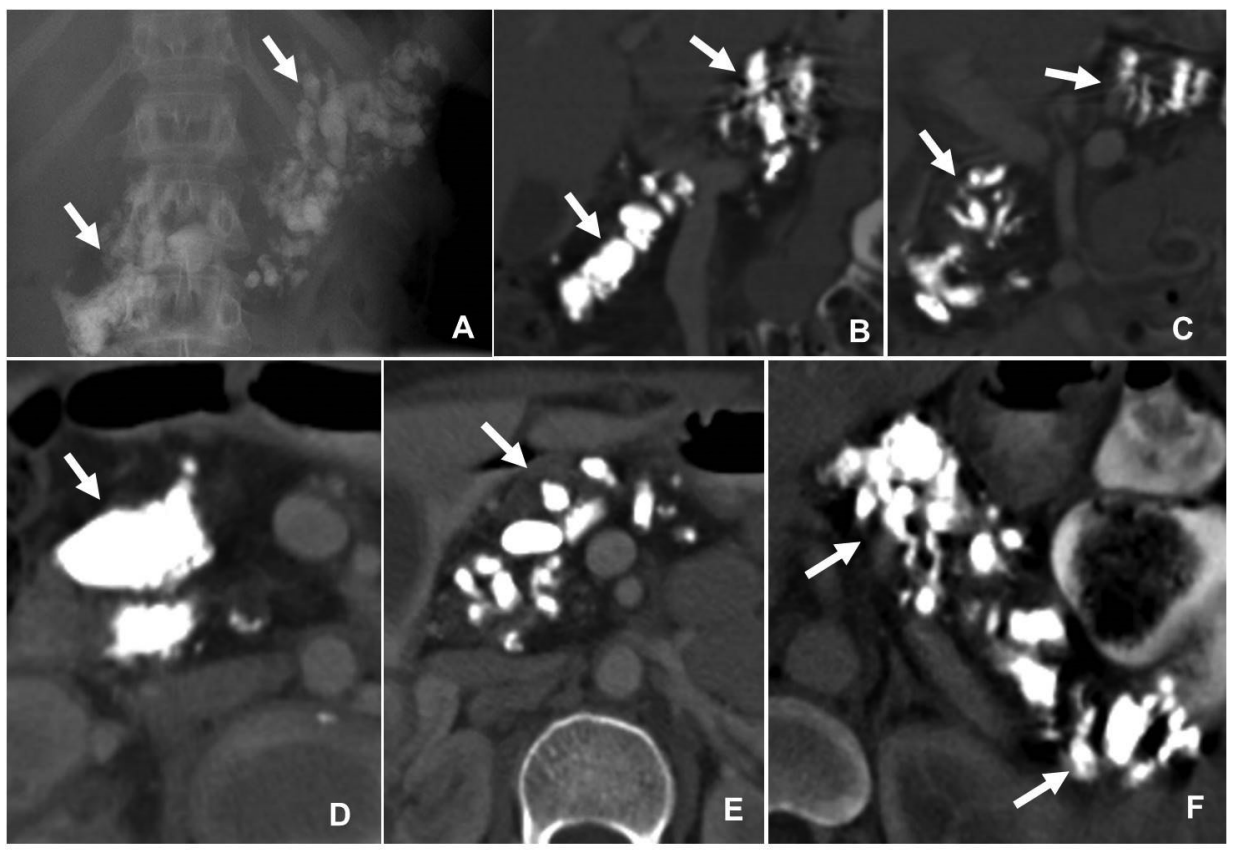

Fig. 5 A 20-year-old male patient with tropical chronic pancreatitis (TCP) and diabetes mellitus. Plain radiograph (A), coronal (B, C) and axial (D-F) contrast computed tomography (CT) images show atrophic pancreas and uniform sized large intraductal calculi distributed throughout the pancreas (A-F, arrow).

pattern is diffusely scattered large intraductal calculi throughout the head, body, and tail region ( - Fig. 5). The second pattern is large calculi distributed predominantly in the head region of the pancreas ( - Fig. 4) ${ }^{23,25,28,29}$ An uncommon pattern is numerous tiny calculi diffusely scattered throughout the gland. This pattern is indistinguishable from alcoholic calcific pancreatitis, which is the most common cause of chronic calcific pancreatitis worldwide. However, the calculi in alcoholic pancreatitis are fine, speckled and have hazy margins, while those in TCP are dense and discrete. The overlap of alcohol abuse in many patients with TCP can make clinical and radiological diagnosis challenging (-Table 1).$^{30}$ Another mimicker of TCP is hereditary pancreatitis, which is a rare autosomal dominant disease occurring in children. The calculi in hereditary pancreatitis are similar to alcoholic pancreatitis however ductal dilatation and pancreatic atrophy is less in comparison to TCP. ${ }^{31}$

Intraductal Papillary Mucinous Neoplasm (IPMN) of the pancreas can clinically present itself as chronic pancreatitis. Moreover, irregular ductal dilatation and intraductal mucin calcification in these patients can make it difficult to differentiate it from TCP by imaging. Demonstration of the presence of intraductal papillary nodules or intraductal mucin, projection of the papilla into the duodenal lumen by CT/MRI, and endoscopy helps differentiate IPMN from TCP. ${ }^{32-35}$

Patients with hyperparathyroidism and hypercalcemia are at increased risk of developing pancreatitis. The mechanism may involve deposition of calcium within the pancreatic duct and excessive conversion of trypsinogen to trypsin catalyzed by calcium. Imaging findings are indistinguishable from alcoholic pancreatitis, showing small pancreatic calcification distributed throughout the pancreas. Lesser degree of ductal dilatation, atrophy of gland, and small size of calcifications help in differentiating it from TCP. ${ }^{36-38}$
Usually, patients with TCP require insulin for diabetes control. ${ }^{39}$ In patients not responding to medical management, surgical management is indicated. Surgical procedures such as Puestow procedure (longitudinal pancreaticojejunostomy), Duval procedure (distal pancreaticojejunostomy), and subtotal pancreatectomy have shown good results. ${ }^{40}$ Most

Table 1 Tropical chronic pancreatitis versus alcoholic pancreatitis

\begin{tabular}{|c|c|c|}
\hline & $\begin{array}{l}\text { Tropical } \\
\text { pancreatitis }\end{array}$ & $\begin{array}{l}\text { Alcoholic } \\
\text { pancreatitis }\end{array}$ \\
\hline $\begin{array}{l}\text { Geographic } \\
\text { distribution }\end{array}$ & Tropical & Temparate \\
\hline Age of onset & Young & Middle age \\
\hline Cassava & High intake & No intake \\
\hline Nutrition & Mal-nourished & Well-nourished \\
\hline Alcoholism & Non-alcoholics & Alcoholics \\
\hline Diabetes & $\begin{array}{l}70 \text { to } 80 \% \text {, before } \\
\text { or with the onset of } \\
\text { pain. Severe, insu- } \\
\text { lin-dependant but } \\
\text { ketosis resistant }\end{array}$ & $\begin{array}{l}50 \% \text {, after the } \\
\text { onset of pain } \\
\text { Mild diabetes }\end{array}$ \\
\hline Pancreatic duct & Markedly dilated & Less dilated \\
\hline Calculi & $\begin{array}{l}\text { Dense,large,discrete, } \\
\text { always large duct, } \\
\text { seldom } \\
\text { parenchymal }\end{array}$ & $\begin{array}{l}\text { Fine, speckled, } \\
\text { hazy margins, } \\
\text { Parenchymal or } \\
\text { small ducts } \\
\text { Rarely large duct }\end{array}$ \\
\hline $\begin{array}{l}\text { Course of } \\
\text { disease }\end{array}$ & Rapid progression & Slow progression \\
\hline Malignancy & Common & Less common \\
\hline
\end{tabular}


deaths in TCP are due to complications secondary to diabetes. Other causes of mortality are severe infections, pancreatic cancer, and pancreatitis-related complications. ${ }^{41}$

\section{Complications}

\section{Acute on Chronic Pancreatitis}

Patients with TCP have recurrent episodes of acute exacerbations. CT is a useful modality to detect early changes. The gland shows focal or diffuse enlargement in the background of CCP. Increased density in the peripancreatic fat, thickening of fascial planes, and fluid collection (intra-pancreatic, peripancreatic space, and lesser sac) indicates acute exacerbation of the disease (-Fig. 6 ). ${ }^{42}$

\section{Pseudocysts}

Evolution of fluid collection into pseudocyst occurs over a period between 4 and 6 weeks. Pseudocysts are composed of a thick, well-defined capsule of dense fibrous connective tissue ( - Fig. 7). Larger pseudocysts $(>5 \mathrm{~cm}$ ) usually do not undergo spontaneous resolution and require intervention. Usually, pseudocysts possess water density attenuation content. Increase in the density of pseudocyst content may be secondary to infection or hemorrhage (hemosucchus pancreaticus).Although CT characterizes the collections/pseudocysts, sometimes MRI/MRCP could be helpful in delineating the ductal communication with the pseudocysts. ${ }^{43}$

\section{Biliary Obstruction}

Biliary obstruction can be secondary to benign distal common bile duct (CBD) strictures or pancreatic head malignancy. Benign strictures show a smooth narrowing of distal CBD with low grade intrahepatic biliary dilatation, whereas pancreatic head malignancy causes abrupt cut off of distal CBD with high grade intrahepatic biliary dilatation ( $\mathbf{- F i g . ~ 8 )} .^{44,45}$

\section{Vascular Complications}

The incidence of pseudoaneurysm of visceral arteries in chronic pancreatitis is 7 to $10 \%$, greater than in acute pancreatitis (1-6\%). ${ }^{46,47}$ Various mechanisms of pseudoaneurysm formation are as follows: enzymatic autodigestion of arterial wall leading to pseudoaneurysm formation, visceral artery eroding into pseudocyst converting pseudocyst into a pseudoaneurysm, and pseudocyst eroding into bowel wall with bleeding from the mucosal surface ( - Fig. 9). TCP frequently causes thrombosis of the splenic vein. ${ }^{46,48}$ Multiphase CT detects the site and cause of the bleed with good sensitivity. It also provides a good vascular roadmap for surgery or embolization. ${ }^{49,50}$

\section{Malignant versus Inflammatory Masses}

Various studies have shown that 7 to $10 \%$ of patients with TCP develop pancreatic carcinoma. Compared with other forms of chronic pancreatitis, malignancy complicating TCP occurs at a much younger age and has a worse prognosis. TCP patients have a hundredfold increased risk of developing pancreatic cancer than controls. ${ }^{50,51}$ A common problem faced in imaging of patients with TCP is to differentiate between the inflammatory mass (pseudotumor) and the pancreatic carcinoma. The shrunken and atrophic pancreas is the most frequent finding in TCP. However, the focal inflammatory process may mimic carcinoma (-Fig. 8). ${ }^{52-54}$ With advances in CT and MRI, various investigators have attempted to differentiate inflammatory mass from carcinoma. Studies show that both inflammatory mass and carcinoma histologically consist of abundant fibrosis, and show hypoenhancement
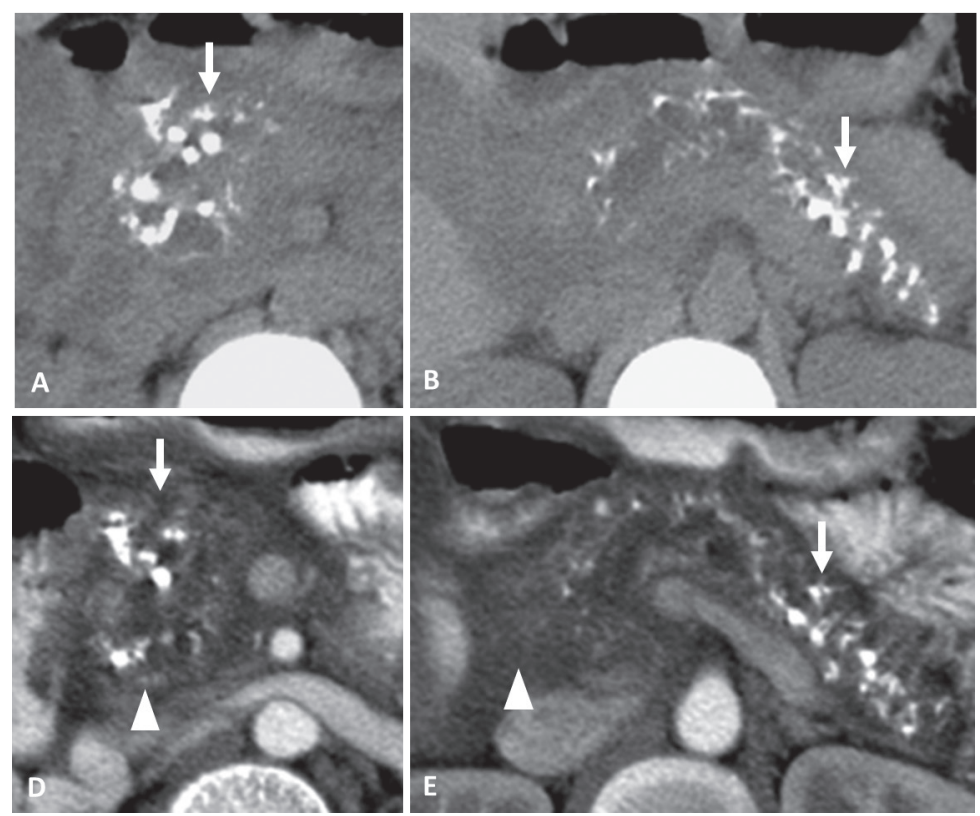
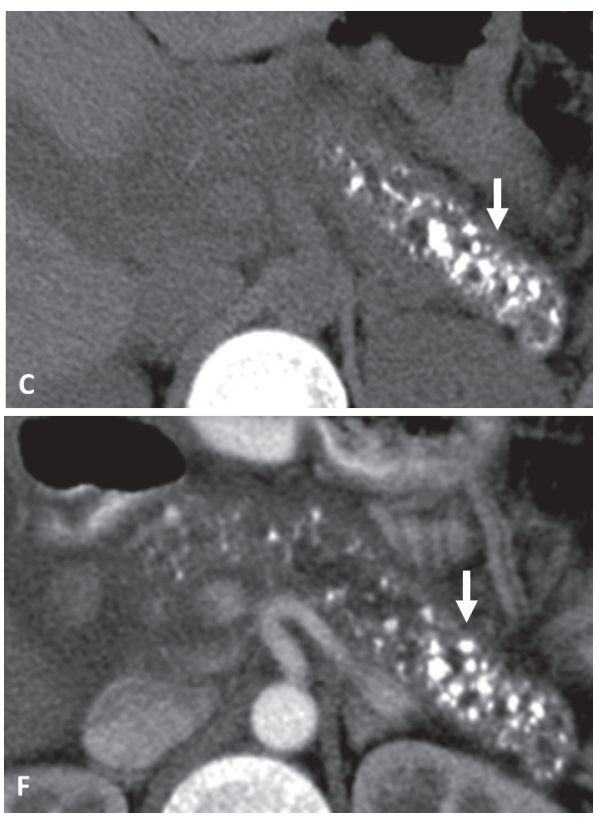

Fig. 6 A 30-year-old male patient with tropical chronic pancreatitis (TCP) presented with acute pain abdomen. Axial plain images (A-C) and axial contrast images (D-F) of Computed tomography (CT) show atrophic pancreas and uniform sized large intraductal calculi distributed throughout the pancreas (A-G arrow). Bulky head of the pancreas ( $\mathbf{D}$, arrowhead) with surrounding fat stranding (E, arrowhead) suggestive of acute on chronic pancreatitis. 


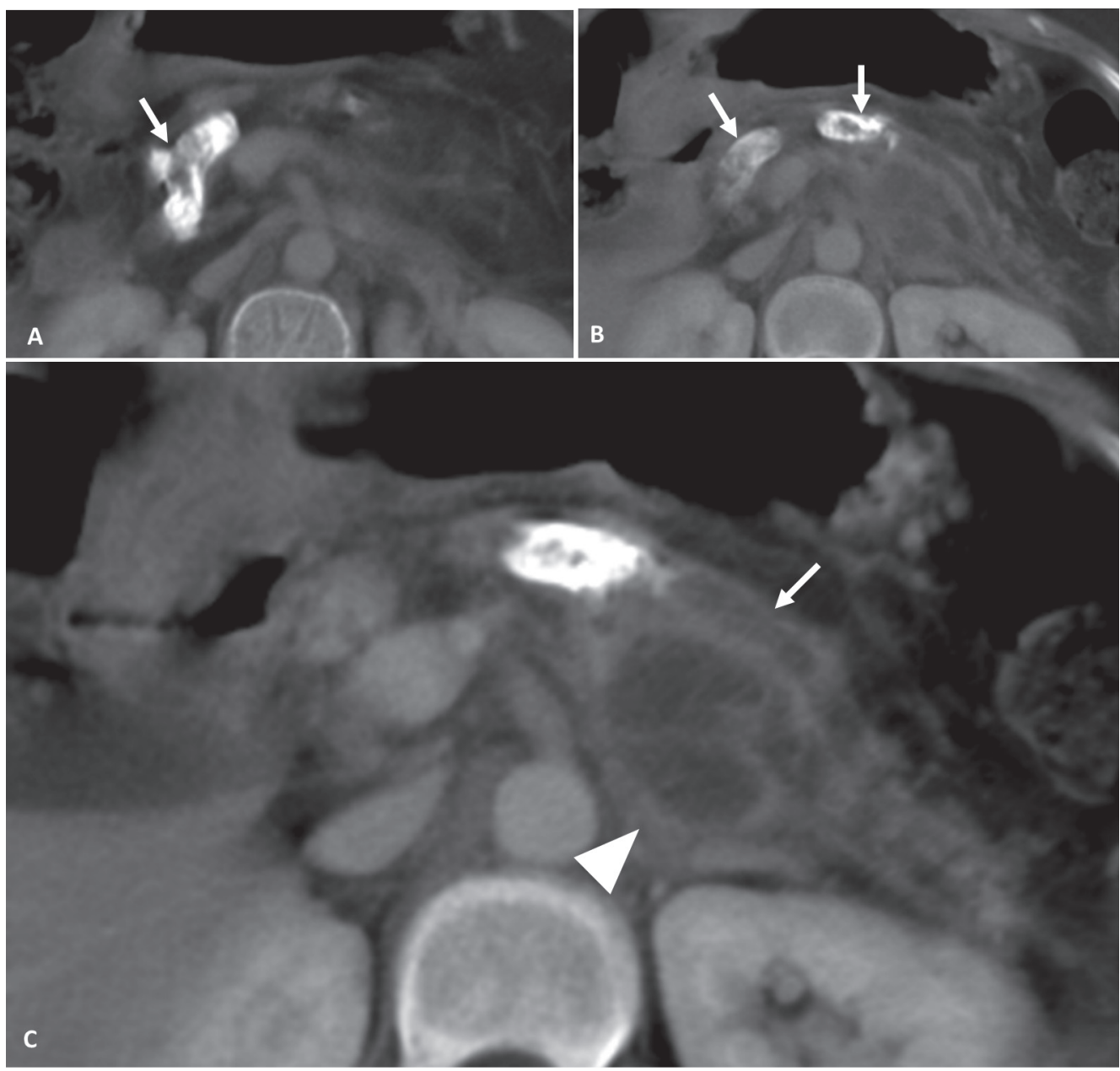

Fig. 7 A 35-year-old male patient with tropical chronic pancreatitis (TCP) with a recurrent episode of acute pancreatitis. Axial contrast CT images show atrophic pancreas, dilated main pancreatic duct (C, arrow), large intraductal calculi in the head (A, arrow), body region (B, arrow) and pseudocyst in the body region of the pancreas (C, arrowhead).
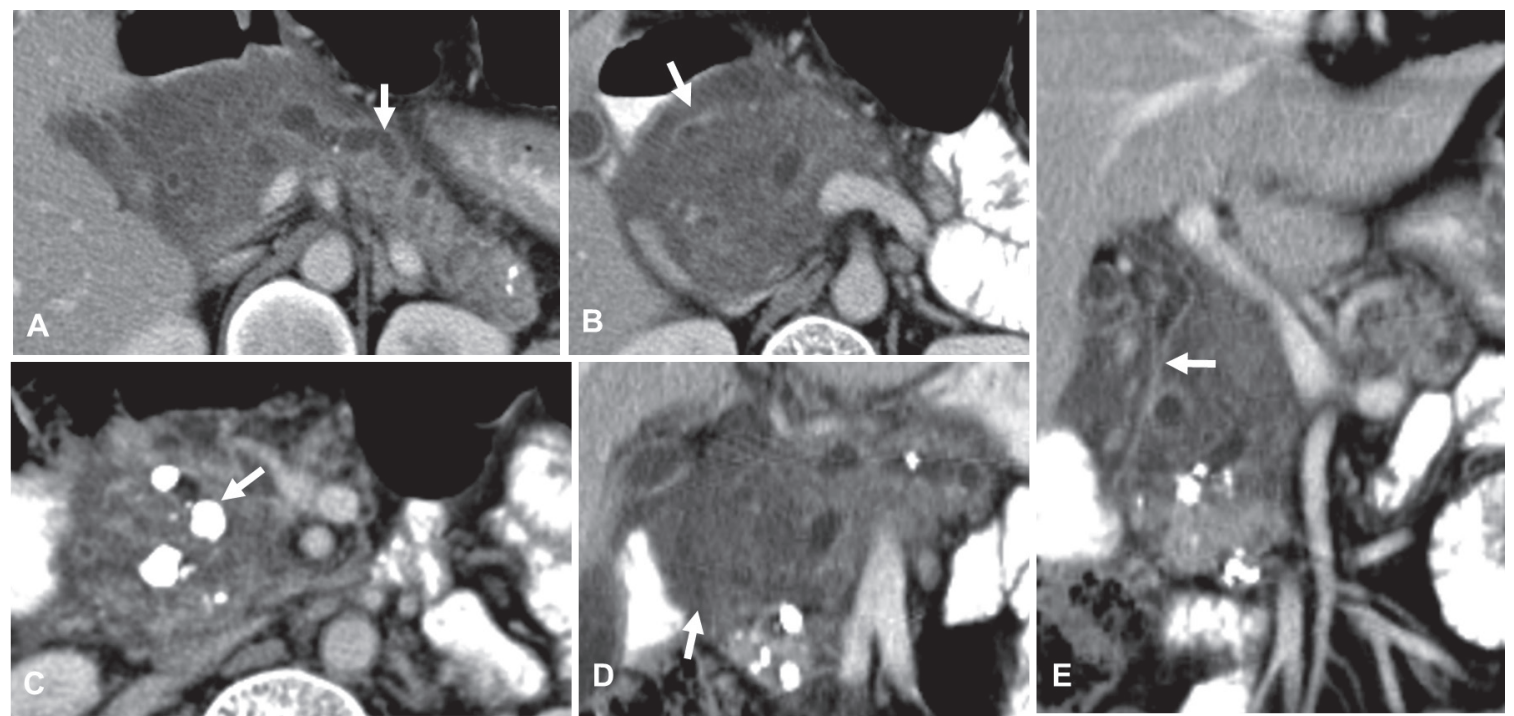

Fig. 8 A 39-year-old male patient with tropical chronic pancreatitis (TCP) with a recurrent episode of acute pancreatitis. Axial (A-C) and coronal (D, E) Contrast CT images show irregular dilated main pancreatic duct (A, arrow) and calcifications in the head region (C, arrow). A hypodense mass in the head region (B, D arrow) causing smooth narrowing of distal CBD (E, arrow) with no significant biliary obstruction. EUS guided biopsy done from head mass and histopathology report was non-malignant inflammatory mass. 
in contrast-enhanced CT or MRI images. Johnson PT et al observed that masses, due to chronic pancreatitis and pancreatic carcinoma, show delayed progressive enhancement on dynamic contrast MRI and attributed this to the abundant fibrosis within these masses. ${ }^{55}$ Kumaresan $S$ et al studied the utility of diffusion-weighted imaging (DWI) in differentiating inflammatory mass from carcinoma and concluded that DWI does not add any additional value with regard to differentiating between the two. ${ }^{56}$ Secondary signs which can point toward malignancy are metastases, the abrupt cutoff of CBD, and vascular invasion (-Fig. 10). ${ }^{44,45}$ Any soft tissue appearing in a completely atrophic gland on follow-up imaging should be treated with high suspicion. Although endoscopic ultrasound (EUS) has high resolution, studies have shown its limited role in differentiating inflammatory mass from carcinoma. EUS provides good guidance for fine needle aspiration (FNA) or biopsy. However, the sensitivity of EUS-FNA for malignancy in parenchymal masses with features of TCP is low (54-74\%). ${ }^{57-61}$ The only reliable method of confirming malignancy is histopathology of the surgical specimen.

\section{Changing Trends in TCP}

Balakrishna et al have extensively studied TCP over a period of 30 years and have observed the changing trends in the TCP. The disease now occurs in older individuals, who have milder diabetes which can be controlled using oral hypoglycemic agents. TCP is now a more heterogeneous disease, sometimes presenting itself in classical form and often resembling idiopathic or alcoholic chronic pancreatitis. In a particular patient, more than one etiological factor may be operating in tandem and their relative contributions determine the manifestations of TCP. ${ }^{1}$

\section{Conclusion}

TCP is a unique, rapidly progressing calcific pancreatitis occurring among younger non-alcoholic patients. It has a higher propensity to develop malignancy at a younger age with a worse prognosis. TCP is also showing a change in pattern, with cases reported from the temperate region and from those afflicted with milder diabetes. The typical

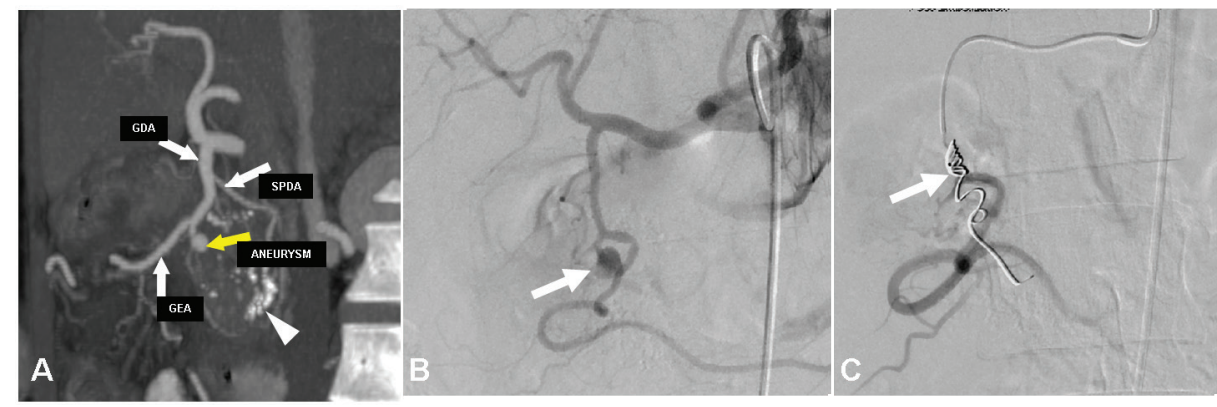

Fig. 9 A 32-year-old male patient with tropical chronic pancreatitis (TCP) with haematemesis. Contrast CT (A) and DSA (B, C) images show calcifications in the head region (A, arrowhead) and pseudoaneurysm from gastroduodenal artery branch (A, yellow arrow; B arrow). Isolation of pseudoaneurysm achieved by coil trapping technique (C, arrow).

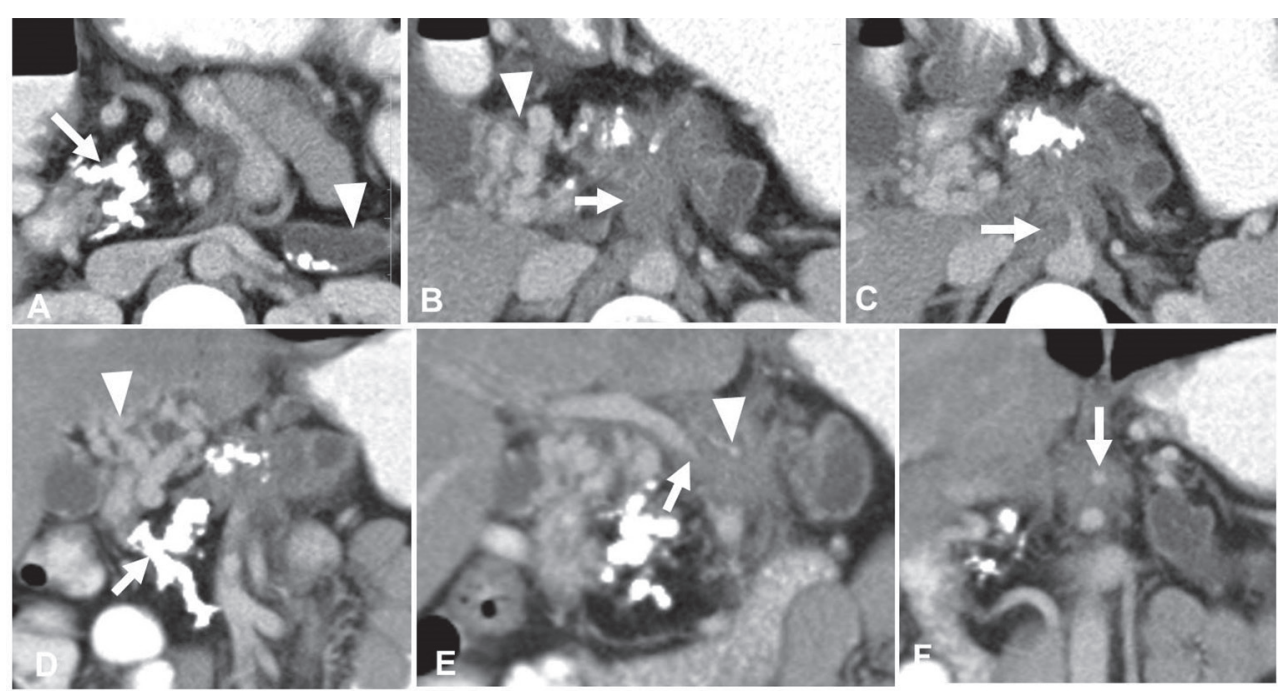

Fig. 10 A 38-year-old female patient with tropical chronic pancreatitis (TCP). Axial (A-C) and coronal (D-F) Contrast CT images show, atrophic pancreas, dilated main pancreatic duct (MPD) (A, arrowhead) with multiple intraductal calculi (A, D arrow). An irregular hypodense mass (B, arrow) in pancreatic body region with encasement and narrowing of celiac artery (C, arrow), hepatic artery (E, arrowhead), SMA (F, arrow) and occlusion of main portal vein (E, arrow) with multiple collaterals at hilum (D, arrowhead). Histopathology report was adenocarcinoma. 
imaging features of this condition helps in differentiating it from other forms of calcific pancreatitis. Awareness of this unique pathogenetic entity will enable the radiologist to recognize it early. Intervention at an early stage, using newer therapeutic approaches, could help to ensure better survival and prognosis. Population-wide genetic studies could help in the prevention of this condition in the future.

\section{Conflict of Interest}

None declared.

\section{References}

1 Balakrishnan V, Nair P, Radhakrishnan L, Narayanan VA. Tropical pancreatitis - a distinct entity, or merely a type of chronic pancreatitis? Indian J Gastroenterol 2006;25(2):74-81

2 Balakrishnan V, Sauniere JF, Hariharan M, Sarles H. Diet, pancreatic function, and chronic pancreatitis in south India and France. Pancreas 1988;3(1):30-35

3 Zuidema PJ. Cirrhosis and disseminated calcification of the pancreas in patients with malnutrition. Trop Geogr Med 1959;11(1):70-74

4 GeeVarghese PJ. Pillai VK, Joseph MP, Pitchumoni CS. The diagnosis of pancreatogenous diabetes mellitus. J Assoc Physicians India 1962;10:173-178

5 Geevarghese PJ, Chronic Pancreatitis and Diabetes Mellitus in the Tropics. Bombay:Varghese Publishing House; 1992:57-60

6 Davies JNP. The essential pathology of kwashiorkor. Lancet 1948;1(6496):317-320

7 Mohan V, Premalatha G. Fibrocalculous pancreatic diabetes. Int J Diabetes 1995;3:71-82

8 Shenoy KT, Shanmugam J, Balakrishnan V. Viral \& Mycoplasma pneumoniae antibodies in chronic pancreatitis of tropics. Indian J Med Res 1986;84:22-26

9 Shanmugam J, Balakrishnan V, George M, Shenoy KT. Study of Coxsackie B viral infections in chronic pancreatitis patients from Kerala. J Postgrad Med 1987;33(1):29-31

10 Mahurkar S, Reddy DN, Rao GV, Chandak GR. Genetic mechanisms underlying the pathogenesis of tropical calcific pancreatitis. World J Gastroenterol 2009;15(3):264-269

11 Bhatia E, Choudhuri G, Sikora SS, et al. Tropical calcific pancreatitis: strong association with SPINK1 trypsin inhibitor mutations. Gastroenterology 2002;123(4):1020-1025

12 McMillan DE, Geevarghese PJ. Dietary cyanide and tropical malnutrition diabetes. Diabetes Care 1979;2(2):202-208

13 Mathangi DC, Namasivayam A, Mohan V. Chronic cassava feeding on pancreatic function and histology in albino rats. In: Proceedings of the Second International Conference of Tropical Gastroenterology and Hepatology, Jaipur. 1996: p. 6.

14 Balakrishnan V, Tropical pancreatitis - epidemiology, pathogenesis and etiology. In: Balakrishnan V, ed. Chronic Pancreatitis in India. Trivandrum: Indian Society of Pancreatology; 1987:79-85

15 Nagalotimath SJ, Pancreatic pathology in pancreatic calcification with diabetes. In: Podolsky S, Viswanathan M, eds. Secondary diabetes: the spectrum of diabetic syndromes. New York: Raven Press; 1980:117-45

16 Nair B., Pathology of tropical calcific pancreatitis. In: Kumar N, Acharya SK, eds. Tropical calcific pancreatitis. Kerala: Roussel Scientific Institute; 1994:83-90

17 Nair B, Latha P, Pancreas in chronic pancreatitis in India. In: Balakrishnan $\mathrm{V}$, ed. Trivandrum: Indian Society of Pancreatology; 1987:115-20

18 Schultz AC, Moore PB, Geevarghese PJ, Pitchumoni CS. X-ray diffraction studies of pancreatic calculi associated with nutritional pancreatitis. Dig Dis Sci 1986;31(5):476-480
19 Pitchumoni CS, Viswanathan KV, Gee Varghese PJ, Banks PA. Ultrastructure and elemental composition of human pancreatic calculi. Pancreas 1987;2(2):152-158

20 Nagalotimath SJ, Pancreatic in Karnataka. A note on pathology. In: Balakrishnan V, ed. Chronic pancreatitis in India. Trivandrum: Indian Society of Pancreatology; 1986:105-111

21 Govindarajan M, Mohan V, Deepa R, Ashok S, Pitchumoni CS. Histopathology and immunohistochemistry of pancreatic islets in fibrocalculous pancreatic diabetes. Diabetes Res Clin Pract 2001;51(1):29-38

22 Bolondi L, Priori P, Gullo L, et al. Relationship between morphological changes detected by ultrasonography and pancreatic exocrine function in chronic pancreatitis. Pancreas $1987 ; 2(2): 222-229$

23 Jones SN, Lees WR, Frost RA. Diagnosis and grading of chronic pancreatitis by morphological criteria derived by ultrasound and pancreatography. Clin Radiol 1988;39(1):43-48

24 Dimcevski G, Erchinger FG, Havre R, Gilja OH. Ultrasonography in diagnosing chronic pancreatitis: new aspects. World J Gastroenterol 2013;19(42):7247-7257

25 Moorthy TR, Nalini N, Narendranathan M. Ultrasound imaging in tropical pancreatitis. J Clin Ultrasound 1992;20(6):389-393

26 Manfredi R, Brizi MG, Masselli G, Gui B, Vecchioli A, Marano P. Imaging of chronic pancreatitis. Rays 2001;26(2):143-149

27 De Backer AI, Mortelé KJ, Ros RR, Vanbeckevoort D, Vanschoubroeck I, De Keulenaer B. Chronic pancreatitis: diagnostic role of computed tomography and magnetic resonance imaging. JBR-BTR 2002;85(6):304-310

28 Luetmer PH, Stephens DH, Ward EM. Chronic pancreatitis: reassessment with current CT. Radiology 1989;171(2):353-357

29 Kusano S, Kaji T, Sugiura Y, Tamai S. CT demonstration of fibrous stroma in chronic pancreatitis: pathologic correlation. J Comput Assist Tomogr 1999;23(2):297-300

30 Chari S, Jayanthi V, Mohan V, Malathi S, Madanagopalan N, Viswanathan M. Radiological appearance of pancreatic calculi in tropical versus alcoholic chronic pancreatitis. J Gastroenterol Hepatol 1992;7(1):42-44

31 Rosendahl J, Bödeker H, Mössner J, Teich N. Hereditary chronic pancreatitis. Orphanet J Rare Dis 2007;2:1-10

32 Procacci C, Graziani R, Bicego E, et al. Intraductal mucinproducing tumors of the pancreas: imaging findings. Radiology 1996;198(1):249-257

33 Sugiyama M, Atomi Y, Hachiya J. Intraductal papillary tumors of the pancreas: evaluation with magnetic resonance cholangiopancreatography. Am J Gastroenterol 1998;93(2):156-159

34 Procacci C, Megibow AJ, Carbognin G, et al. Intraductal papillary mucinous tumor of the pancreas: a pictorial essay. Radiographics 1999;19(6):1447-1463

35 Fukukura Y, Fujiyoshi F, Sasaki M. Inoue H, Yonezawa S, Nakajo M. Intraductal papillary mucinous tumors of the pancreas: thin-section helical CT findings. AJR. Am J Roentgenol 2000;174(2):441-447

36 Carnaille B, Oudar C, Pattou F, Combemale F, Rocha J, Proye C. Pancreatitis and primary hyperparathyroidism: forty cases. Aust N Z J Surg 1998;68(2):117-119

37 Mithöfer K, Fernández-del Castillo C, Frick TW, Lewandrowski KB, Rattner DW, Warshaw AL. Acute hypercalcemia causes acute pancreatitis and ectopic trypsinogen activation in the rat. Gastroenterology 1995;109(1):239-246

38 Prinz RA, Aranha GV. The association of primary hyperparathyroidism and pancreatitis. Am Surg 1985;51(6):325-329

39 Mohan V, Premalatha G, Pitchumoni CS. Tropical chronic pancreatitis: an update. J Clin Gastroenterol 2003;36(4):337-346

40 Thomas PG, Augustine P, Ramesh H, Rangabashyam N. Observations and surgical management of tropical pancreatitis in Kerala and southern India. World J Surg 1990;14(1):32-42 
41 Mohan V, Premalatha G, Padma A, Chari ST, Pitchumoni CS. Fibrocalculous pancreatic diabetes. Long-term survival analysis. Diabetes Care 1996;19(11):1274-1278

42 Elmas N. The role of diagnostic radiology in pancreatitis. Eur J Radiol 2001;38(2):120-132

43 Perez-Johnston R, Sainani NI, Sahani DV. Imaging of chronic pancreatitis (including groove and autoimmune pancreatitis) Radiol Clin North Am 2012;50(3):447-466

44 Petrozza JA, Dutta SK. The variable appearance of distal common bile duct stenosis in chronic pancreatitis. J Clin Gastroenterol 1985;7(5):447-450

45 Perumal S, Palaniappan R, Pillai SA, Velayutham V, Sathyanesan J. Predictors of malignancy in chronic calcific pancreatitis with head mass. World J Gastrointest Surg 2013;5(4):97-103

46 Flati G, Andrén-Sandberg A, La Pinta M, Porowska B, Carboni M. Potentially fatal bleeding in acute pancreatitis: pathophysiology, prevention, and treatment. Pancreas 2003;26(1):8-14

47 Kulkarni CB, Moorthy S, Pullara SK, Prabhu NK, Kannan RR, Nazar PK. Endovascular management of pancreatitis related pseudoaneurysms-A single center experience. Gastrointest Interv. 2014;3(1):46-53

48 Andersson E, Ansari D, Andersson R. Major haemorrhagic complications of acute pancreatitis. BrJSurg 2010;97(9):1379-1384

49 Saad NE, Saad WE, Davies MG, Waldman DL, Fultz PJ, Rubens DJ. Pseudoaneurysms and the role of minimally invasive techniques in their management. Radiographics 2005;25(Suppl 1):S173-S189

50 Kulkarni C, Moorthy S, Sreekumar K, et al. In the workup of patients with obscure gastrointestinal bleed, does 64-slice MDCT have a role? Indian J Radiol Imaging 2012;22(1):47-53

51 Chari ST, Mohan V, Pitchumoni CS, Viswanathan M, Madanagopalan N, Lowenfels AB. Risk of pancreatic carcinoma in tropical calcifying pancreatitis: an epidemiologic study. Pancreas 1994;9(1):62-66

52 Falconi M, Casetti L, Salvia R, et al. Pancreatic head mass, how can we treat it? Chronic pancreatitis: surgical treatment. JOP 2000;1(3, Suppl) :154-161
53 Beger HG, Schlosser W, Friess HM, Büchler MW. Duodenum-preserving head resection in chronic pancreatitis changes the natural course of the disease: a single-center 26-year experience. Ann Surg 1999;230(4):512-519, discussion 519-523

54 Pulay I, Tihanyi TF, Flautner L. Pancreatic head mass: what can be done? Classification: the clinical point of view. JOP 2000;1(3, Suppl):85-90

55 Johnson PT, Outwater EK. Pancreatic carcinoma versus chronic pancreatitis: dynamic MR imaging. Radiology 1999;212(1):213-218

56 Sandrasegaran K, Nutakki K, Tahir B. Dhanabal A, Tann M, Cote GA. Use of diffusion-weighted MRI to differentiate chronic pancreatitis from pancreatic cancer. AJR. Am J Roentgenol 2013;201(5):1002-1008

57 Fritscher-Ravens A, Brand L, Knöfel WT, et al. Comparison of endoscopic ultrasound-guided fine needle aspiration for focal pancreatic lesions in patients with normal parenchyma and chronic pancreatitis. Am J Gastroenterol 2002;97(11):2768-2775

58 Barthet M, Portal I, Boujaoude J, Bernard JP, Sahel J. Endoscopic ultrasonographic diagnosis of pancreatic cancer complicating chronic pancreatitis. Endoscopy 1996;28(6):487-491

59 Ardengh JC, Lopes CV, Campos AD, Pereira de Lima LF, Venco F, Módena JL. Endoscopic ultrasound and fine needle aspiration in chronic pancreatitis: differential diagnosis between pseudotumoral masses and pancreatic cancer. JOP 2007;8(4):413-421

60 Varadarajulu S, Tamhane A, Eloubeidi MA. Yield of EUS-guided FNA of pancreatic masses in the presence or the absence of chronic pancreatitis. Gastrointest Endosc 2005;62(5):728736, quiz 751, 753

61 Krishna NB, Mehra M, Reddy AV, Agarwal B. EUS/EUS-FNA for suspected pancreatic cancer: influence of chronic pancreatitis and clinical presentation with or without obstructive jaundice on performance characteristics. Gastrointest Endosc 2009;70(1):70-79 